\title{
Assessment of carboprost tromethamine for reducing hemorrhage in laparoscopic intramural myomectomy
}

\author{
RUITAO ZHANG, HUIRONG SHI, FANG REN and ZHONGFU YUAN
}

Department of Gynecology, First Affiliated Hospital, Zhengzhou University, Zhengzhou, Henan 450052, P.R. China

Received January 7, 2015; Accepted July 2, 2015

DOI: $10.3892 /$ etm.2015.2649

\begin{abstract}
The aim of the present study was to evaluate the effect of carboprost tromethamine on blood loss during laparoscopic myomectomy (LM) in females. Ninety women, who were scheduled for LM due to symptomatic uterine myomas, were randomly divided into three groups. Twenty-four women were intramyometrially injected with 12 IU diluted vasopressin (vasopressin group), 30 cases received a deep intramuscular injection of $250 \mu \mathrm{g}$ carboprost tromethamine $30 \mathrm{~min}$ prior to myomectomy (carboprost group), and 36 cases received an intramuscular injection of $250 \mu \mathrm{g}$ carboprost tromethamine followed by a 20 IU oxytocin intravenous infusion at a rate of $120 \mathrm{mU} / \mathrm{min}$ during the procedure (carboprost plus oxytocin group). The procedure time, amount of hemorrhage, postoperative reduction in hemoglobin levels, adverse effects, bowel deflation time and time of postoperative hospital stay were compared. The procedure time, amount of hemorrhage and postoperative reduction in hemoglobin levels were not significantly different between the carboprost group and the vasopressin group $(\mathrm{P}>0.05)$. In the carboprost plus oxytocin group, the procedure time, amount of hemorrhage and postoperative reduction in hemoglobin levels were $24.3 \pm 2.6 \mathrm{~min}$, $51.1 \pm 8.4 \mathrm{ml}$ and $6.9 \pm 1.5 \mathrm{~g} / 1$, respectively, which were significantly less than those in the vasopressin and carboprost groups (all $\mathrm{P}<0.05)$. In the carboprost and carboprost plus oxytocin groups, the incidence of mild uterine contraction pain was significantly higher than in the vasopressin group $\left(\chi^{2}=12.913, \mathrm{P}=0.002\right)$. The incidences of other side-effects were not significantly different among the three groups. The times for bowel deflation and postoperative hospital stay were marginally increased in both the carboprost and carboprost plus oxytocin groups, compared with the vasopressin group, although no significant differences were found among the three groups $(\mathrm{P}>0.05)$. Deep intramuscular injections of
\end{abstract}

Correspondence to: Professor Huirong Shi, Department of Gynecology, First Affiliated Hospital, Zhengzhou University, 1 Jianshe Road, Zhengzhou, Henan 450052, P.R. China

E-mail: huirongshizzu@yahoo.com

Key words: vasopressin, oxytocin, carboprost tromethamine, laparoscopic intramural myomectomy carboprost tromethamine prior to performing myomectomy could be an effective approach for reducing blood loss from intramural LM, in particular when combined with oxytocin intravenous infusion.

\section{Introduction}

Myomas, also known as fibroids, are benign smooth muscle tumors of the uterus. Two-thirds of women with fibroids are often symptomless but the remaining third present with symptoms that are severe enough to warrant removing the myomas surgically (1). For women who are considering future childbearing or simply wish to preserve their uterus, the standard treatment of symptomatic fibroids is myomectomy. Abdominal myomectomy, transvaginal myomectomy, laparoscopic myomectomy (LM), laparoscopic-assisted myomectomy through a mini-laparotomy incision, and robotic-assisted laparoscopic myomectomy are alternative approaches in gynecological myomectomy practice. Recent technological advances in endoscopy have allowed gynecological surgeons to implement myomectomy practice laparoscopically (2-4). LM is a priority approach for women with fibroids who are suitable for laparoscopic procedures.

The safety and efficacy of LM is associated with the control of bleeding during the performance of the procedure. Prevention of bleeding makes correct dissection during LM easier. Skillful surgical techniques may decrease operative blood loss and blood transfusion rate, and the results will be better when combined with other hemorrhage-reducing approaches. Vasopressin and oxytocin are often used to control blood loss during LM $(5,6)$. The antidiuretic hormone vasopressin is often used locally to the uterus to reduce blood loss during surgery (7). Carboprost tromethamine is mainly used for the prevention of postpartum hemorrhage and hemorrhage associated with abortion in the second trimester of pregnancy (between 13 and 20 weeks). Carboprost tromethamine can also prevent postpartum hemorrhage effectively in cesarean deliveries (8). The present study aimed to evaluate the hemorrhage-reducing effects of carboprost tromethamine during LM.

\section{Patients and methods}

Patients. Ninety women who were scheduled to undergo LM for symptomatic intramural fibroids were collected from 
Table I. Differences in procedure time, hemorrhage and hemoglobin reduction in the three groups.

\begin{tabular}{lccccccc}
\hline Group & $\mathrm{N}$ & $\begin{array}{c}\text { Procedure } \\
\text { time }(\mathrm{min})\end{array}$ & P-value & $\begin{array}{c}\text { Hemorrhage } \\
(\mathrm{ml})\end{array}$ & P-value & $\begin{array}{c}\text { Hemoglobin } \\
\text { reduction }(\mathrm{g} / \mathrm{l})\end{array}$ & P-value \\
\hline Vasopressin & 24 & $31.2 \pm 5.1$ & & $74.9 \pm 7.3$ & & $11.4 \pm 2.1$ & \\
Carboprost & 30 & $32.7 \pm 3.4$ & $0.152^{\mathrm{a}}$ & $76.4 \pm 6.1$ & $0.098^{\mathrm{a}}$ & $10.3 \pm 3.0$ & $0.102^{\mathrm{a}}$ \\
Carboprost plus oxytocin & 36 & $24.3 \pm 2.6$ & $0.017^{\mathrm{b}}$ & $51.1 \pm 8.4$ & $0.021^{\mathrm{b}}$ & $6.9 \pm 1.5$ & $0.009^{\mathrm{b}}$ \\
\hline
\end{tabular}

${ }^{\mathrm{a}} \mathrm{P}<0.05$ compared with the vasopressin group, ${ }^{\mathrm{b}} \mathrm{P}<0.05$ compared with the vasopressin and carboprost groups.

the Department of Gynecology, First Affiliated Hospital of Zhengzhou University (Zhengzhou, China) from April 2012 to August 2014. Enrolled patients had a single or $<4$ intramural fibroids and suffered from an increase in menstrual flow and/or anemia, and/or pelvic pressure symptoms and/or intercourse discomfort. The diameter of a single myoma ranged from 35 to $82 \mathrm{~mm}$. The median age of the enrolled patients was 35 years (range, 18-46 years). All the enrolled patients were scheduled to undergo LM for the first time, and had not received any medication in nearly 3 months. Patients with coagulation disorders or contraindications for receiving prostaglandin drugs were excluded from the present study. The consent of all enrolled patients was obtained for using carboprost tromethamine prior to surgery, and the present study was approved by the Local Ethics Committee of Zhengzhou University. Enrolled patients were randomly divided into three groups, and received vasopressin, carboprost tromethamine and carboprost tromethamine combined with oxytocin during the LM procedure, respectively. There were no significant differences in patient age, body weight and myoma numbers among the three groups.

Interventions. LM was performed on all patients under intravenous general anesthesia by the same experienced anesthesia team. Patients in the vasopressin group were intramyometrially injected with $12 \mathrm{IU}$ vasopressin (Xinbai Pharmaceutical Co. Ltd., Nanjing, China) diluted with $40 \mathrm{ml}$ saline solution. In the carboprost groups, women received a deep intramuscular injection of $250 \mu \mathrm{g}$ carboprost tromethamine (Changzhou Siyao Pharmaceutical Co. Ltd., Changzhou, China) $30 \mathrm{~min}$ prior to undergoing myomectomy. The remaining patients were intramuscularly injected with $250 \mu \mathrm{g}$ carboprost tromethamine $30 \mathrm{~min}$ prior to the myomectomy, and then received an intravenous infusion of $20 \mathrm{IU}$ oxytocin (Xinbai Pharmaceutical Co. Ltd.) in $250 \mathrm{ml} 5 \%$ glucose solution at a rate of $120 \mathrm{mU} / \mathrm{min}$ during the $\mathrm{LM}$ procedure. All the LM procedures for the enrolled patients were performed by the same surgical team. Data were recorded including the procedure time, amount of hemorrhage, postoperative reduction in hemoglobin levels, adverse events, bowel deflation time and time of postoperative hospital stay. The surgery time was defined as the time from the incision of the uterus myometrium by monopolar coagulation device to the end of laparoscopic pneumoperitoneum, with the exclusion of the time taken to crush and remove fibroids. Amount of hemorrhage $=$ amount of liquid inside the suction device during the LM procedure - amount of saline solution used for rinsing the pelvis during surgery. The reduction in hemoglobin levels was defined as the difference in hemoglobin levels between pre-surgery and $24 \mathrm{~h}$ following the surgery. Bowel deflation time was calculated from the end of intravenous general anesthesia.

Statistical analysis. Measurement data are expressed as mean \pm standard deviation. Counted data are expressed as percentages. Measurement data were analyzed by one-way analysis of variance and Bonferroni test using the SPSS software package, version 17.0 (SPSS, Inc., Chicago, IL, USA). Count data were analyzed by $\chi^{2}$ and Fisher's exact tests. Differences were considered statistically significant when the P-value was $<0.05$.

\section{Results}

Procedure time, hemorrhage and reduction in hemoglobin levels. There were no evident differences between the vasopressin and carboprost groups regarding procedure time, amount of hemorrhage and postoperative hemoglobin reduction but all were markedly different from those of the carboprost plus oxytocin group (Table I).

Adverse effects. Transient increases of blood pressure, heart rate, breathing and airway pressure, and transient reductions of oxygen saturation were common intra-operative complications in the three groups (Table II). There were no clear differences in the incidence of intra-operative complications among the three groups. Mild uterine contraction pain, low fever, nausea, mild vomiting and diarrhea were common postoperative complications in the three groups (Table III). The incidence of mild uterine contraction pain in the vasopressin group was significantly lower than in the other two groups $\left(\chi^{2}=12.913, \mathrm{P}=0.002\right)$.

Time of bowel deflation and postoperative hospital stay. The bowel deflation times were $26.3 \pm 4.8 \mathrm{~h}, 28.6 \pm 5.2 \mathrm{~h}$ and $30.1 \pm 3.6 \mathrm{~h}$ in the vasopressin, carboprost and carboprost plus oxytocin groups, respectively. The times of postoperative stay were $73.3 \pm 3.1 \mathrm{~h}, 80.1 \pm 5.0 \mathrm{~h}$ and $82.7 \pm 4.4 \mathrm{~h}$ in the vasopressin, carboprost and carboprost plus oxytocin groups, respectively. The times of bowel deflation and postoperative stay were marginally increased in the carboprost and carboprost plus oxytocin groups compared with the vasopressin group; however, no significant differences were found among the three groups (Fig. 1). 
Table II. Intra-operative complications in the three groups.

\begin{tabular}{|c|c|c|c|c|}
\hline Variables & $\begin{array}{l}\text { Vasopressin } \\
\text { group }(n=24)\end{array}$ & $\begin{array}{l}\text { Carboprost } \\
\text { group }(n=30)\end{array}$ & $\begin{array}{l}\text { Carboprost plus oxytocin } \\
\text { group }(n=36)\end{array}$ & P-value \\
\hline Blood pressure & $6(25.0)$ & $7(23.3)$ & $8(22.2)$ & 0.969 \\
\hline Heart rate & $3(12.5)$ & $4(13.3)$ & $6(16.7)$ & $0.867^{\mathrm{a}}$ \\
\hline Breathing & $2(8.3)$ & $3(10.0)$ & $5(13.9)$ & $0.838^{\mathrm{a}}$ \\
\hline Airway pressure & $1(4.2)$ & $3(10.0)$ & $3(8.3)$ & $0.791^{\mathrm{a}}$ \\
\hline Oxygen saturation & $4(16.7)$ & $4(13.3)$ & $7(19.4)$ & $0.936^{\mathrm{a}}$ \\
\hline
\end{tabular}

Data are shown as number (percentage). ${ }^{\text {a }}>0.05$ Fisher's exact test.

Table III. Postoperative complications in the three groups.

\begin{tabular}{|c|c|c|c|c|}
\hline Variables & $\begin{array}{l}\text { Vasopressin } \\
\text { group }(n=24)\end{array}$ & $\begin{array}{l}\text { Carboprost } \\
\text { group }(n=30)\end{array}$ & $\begin{array}{c}\text { Carboprost plus } \\
\text { oxytocin group }(n=36)\end{array}$ & P-value \\
\hline Uterine contraction pain & $1(4.2)$ & $12(40.0)$ & $17(47.2)$ & $0.002^{\mathrm{a}}$ \\
\hline Fever & $1(4.2)$ & $4(13.3)$ & $6(16.7)$ & $0.396^{\mathrm{b}}$ \\
\hline Nausea & $3(12.5)$ & $5(16.7)$ & $7(19.4)$ & $0.883^{\mathrm{b}}$ \\
\hline Vomiting & $1(4.2)$ & $2(6.7)$ & $4(11.1)$ & $0.698^{\mathrm{b}}$ \\
\hline Diarrhea & $1(4.2)$ & $3(10.0)$ & $5(16.7)$ & $0.555^{\mathrm{b}}$ \\
\hline
\end{tabular}

Data are shown as number (percentage). ${ }^{\mathrm{a}} \mathrm{P}<0.05,{ }^{\mathrm{b}} \mathrm{P}>0.05$ Fisher's exact test.

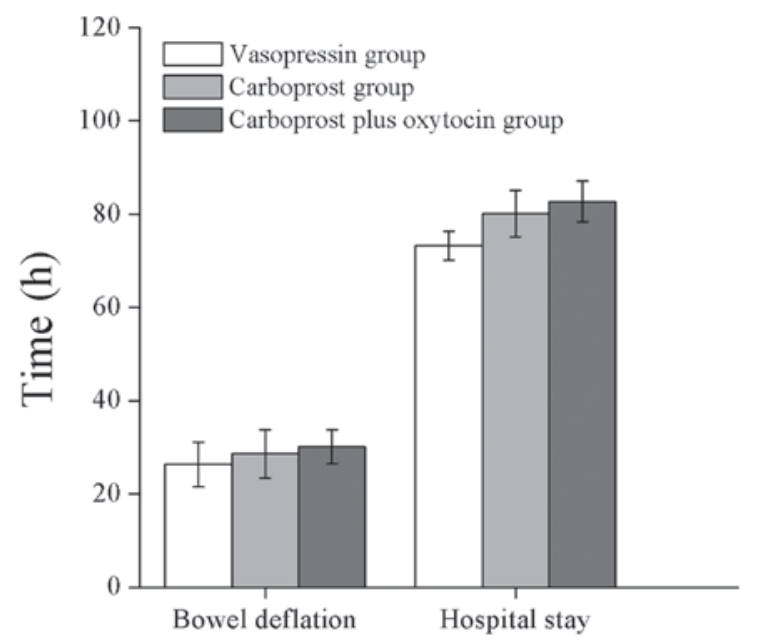

Figure 1. Time of bowel deflation and postoperative hospital stay in the different groups. Each bar represents the mean \pm standard deviation.

\section{Discussion}

LM is a commonly used method of management of uterine myomas, however, the bleeding or blood staining of tissues may prevent gynecological surgeons from completing the dissection correctly. The local use of vasopressin, intravenous oxytocin, vaginal misoprostol, temporary blockage of the uterine artery, and loop ligation of the myoma pseudocapsule are all intra-operative approaches to control blood loss in LM $(9,10)$. Local administration of vasopressin to the myome- trium has been verified to effectively reduce the regional blood flow from the uterine artery to the peripheral vessels, and is a safe hemostatic technique for use in the LM procedure (7). Carboprost tromethamine, a synthetic 15-methyl analog of prostaglandin F2 $\alpha$, is effective at reducing persistent hemorrhage due to uterine atony in delivery (11). Carboprost tromethamine has also been shown to effectively prevent and control postpartum hemorrhage $(12,13)$.

The present study showed that the surgery time, amount of hemorrhage and postoperative reduction in hemoglobin levels were not significantly different between the carboprost and vasopressin groups but were clearly decreased in the carboprost plus oxytocin group. These data indicated that deep intramuscular injections of carboprost tromethamine and myometrial injections of vasopressin had similar hemostatic effects in the LM procedure, and that carboprost tromethamine combined with a continuous intravenous infusion of oxytocin had a superior hemostatic effect.

Vasopressin and oxytocin can cause uterine and gastrointestinal smooth muscle contraction. Vasopressin is associated with hypertension, due to its vasoconstrictive properties, as well as uterine contraction pain, nausea and vomiting (14-16). Chest tightness, palpitations, uterine contraction pain, low fever, nausea, vomiting and diarrhea are common adverse effects of oxytocin $(17,18)$. Carboprost tromethamine can cause prostaglandin-like side-effects, such as nausea, vomiting, diarrhea, headaches, hypertension, fever and bronchial asthma (8).

The present data showed that the incidence of mild uterine contraction pain was higher in the groups using carboprost tromethamine than in the vasopressin-treated 
patients; however, the incidence of the other above-mentioned side-effects was not evidently different among the three groups. The bowel deflation time indicates the recovery of gastrointestinal motility, and influences the postoperative recovery of patients. Though the times of bowel deflation and postoperative stay were marginally increased in the patients treated with carboprost tromethamine, no clear differences were found among the three groups in the present study. The current results indicate that carboprost tromethamine may have stronger effects on the uterine and gastrointestinal smooth muscle than vasopressin and oxytocin. Even though carboprost tromethamine had marginal, yet manageable, adverse effects on gastrointestinal smooth muscle, the evident hemostatic effect should be considered valuable by the clinicians in the LM procedure.

In conclusion, according to the limited number of enrolled patients and the data captured in the present study, it was shown that a deep intramuscular injection of carboprost tromethamine prior to performing myomectomy could be an effective approach for reducing blood loss in laparoscopic intramural myomectomy, in particular when combined with an intravenous infusion of oxytocin.

\section{Acknowledgements}

The authors would like to thank Zheying Liu, Yanyan Jia and Wenlong Feng for their support with data collection. This study was supported by the Hospital Youth Fund Project of the First Affiliated Hospital of Zhengzhou University.

\section{References}

1. Kongnyuy EJ and Wiysonge CS: Interventions to reduce haemorrhage during myomectomy for fibroids. Cochrane Database Syst Rev 8: CD005355, 2014.

2. Rovio PH and Heinonen PK: Transvaginal myomectomy with screw traction by colpotomy. Arch Gynecol Obst 273: 211-215, 2006.

3. Fukuda M, Tanaka T, Kamada M, Hayashi A, Yamashita Y, Terai Y and Ohmichi M: Comparison of the perinatal outcomes after laparoscopic myomectomy versus abdominal myomectomy. Gynecol Obstet Invest 76: 203-208, 2013.
4. Soto E, Flyckt R and Falcone T: Endoscopic management of uterine fibroids: An update. Minerva Ginecol 64: 507-520, 2012.

5. Trehan N: Laparoscopic myomectomy: Methods to control bleeding. J Gynecol Endosc Surg 2: 33-35, 2011.

6. Wang CJ, Lee CL, Yuen LT, Kay N, Han CM and Soong YK: Oxytocin infusion in laparoscopic myomectomy may decrease operative blood loss. J Minim Invasive Gynecol 14: 184-188, 2007.

7. Shimanuki H, Takeuchi H, Kitade M, Kikuchi I, Kumakiri J and Kinoshita K: The effect of vasopressin on local and general circulation during laparoscopic surgery. J Minim Invasive Gynecol 13: 190-194, 2006.

8. Bai J, Sun Q and Zhai H: A comparison of oxytocin and carboprost tromethamine in the prevention of postpartum hemorrhage in high-risk patients undergoing cesarean delivery. Exp Ther Med 7: 46-50, 2014.

9. Matsuoka S, Kikuchi I, Kitade M, Kumakiri J, Kuroda K, Tokita S, Kuroda M and Takeda S: Strategy for laparoscopic cervical myomectomy. J Minim Invasive Gynecol 17: 301-305, 2010.

10. Zhao F, Jiao Y, Guo Z, Hou R and Wang M: Evaluation of loop ligation of larger myoma pseudocapsule combined with vasopressin on laparoscopic myomectomy. Fertil Steril 95: 762-766, 2011.

11. Buttino L Jr and Garite TJ: The use of 15 methyl F2 alpha prostaglandin (Prostin 15 M) for the control of postpartum hemorrhage. Am J Perinatol 3: 241-243, 1986.

12. Abdel-Aleem H, Abol-Oyoun EM, Moustafa SA, Kamel HS and Abdel-Wahab HA: Carboprost trometamol in the management of the third stage of labor. Int J Gynaecol Obstet 42: 247-250, 1993.

13. Vaid A, Dadhwal V, Mittal S, Deka D, Misra R, Sharma JB and Vimla N: A randomized controlled trial of prophylactic sublingual misoprostol versus intramuscular methyl-ergometrine versus intramuscular 15-methyl PGF2 alpha in active management of third stage of labor. Arch Gynecol Obstet 280: 893-897, 2009.

14. Hauksson A, Akerlund M and Melin P: Uterine blood flow and myometrial activity at menstruation, and the action of vasopressin and a synthtic antagonist. Br J Obstet Gynaecol 95: 898-904, 1988.

15. Caras SD, Soykan I, Beverly V, Lin Z and McCallum RW: The effect of intravenous vasopressin on gastric myoelectrical activity in human subjects. Neurogastroenterol Motil 9: 151-156, 1997.

16. Bankir L, Bouby N and Ritz E: Vasopressin: A novel target for the prevention and retardation of kidney disease? Nat Rev Nephrol 9: 223-239, 2013.

17. Tehseen F, Anwar A and Arfat Y: Intraumbilical veinous injection oxytocin in the active management of third stage of labour. J Coll Physicians Surg Pak 18: 551-554, 2008.

18. Ozalp E, Tanir HM and Sener T: Dinoprostone vaginal insert versis intravenous oxytocin to reduce postpartum blood loss following vaginal or cesarean delivery. Clin Exp Obstet Gynecol 37: 53-55, 2010. 